\title{
Multiple drug resistance of Campylobacter jejuni and Shigella isolated from diarrhoeic children at Kapsabet County referral hospital, Kenya
}

Ongwae H. Zachariah ${ }^{1}$, Mwamburi A. Lizzy ${ }^{2 *}$, Kakai Rose ${ }^{3}$ and Mutuku M. Angela ${ }^{4}$

\begin{abstract}
Background: Diarrhoea is a common cause of mortality and morbidity in children under five years old. In Kenya, it has a $21 \%$ case fatality with Enteropathogenic E. coli, Campylobacter jejuni, Shigella spp. and Salmonella spp. accounting for 50-60\% of the cases. Sulphonamides, tetracycline, ampicillin and trimethoprim/sulfamethoxazole are typically used in the treatment of diarrhoeal diseases but have become ineffective in the face of emerging antimicrobial resistance. The objective of this study was to evaluate the prevalence and antimicrobial susceptibility of Campylobacter jejuni and Shigella species in children under five years of age presenting with diarrhoea at Kapsabet County Referral Hospital in Kenya.

Methods: Faecal samples were collected from 139 children admitted with diarrhoea. Each sample was examined macroscopically for colour, texture, and presence of extraneous material. The samples were then cultured for bacterial growth. Observed bacterial growth was isolated and identified by a series of biochemical tests. Resistance patterns were also evaluated using the Kirby - Bauer Disk diffusion method. The chi - square test and Pearson Correlation Coefficient were used to establish statistical significance.

Results: Approximately $33.1 \%$ of the total faecal samples tested were positive for enteric pathogens. Shigella spp. demonstrated resistance to erythromycin (91.7\%), doxycyclin (83.3\%), ampicillin (82.1\%), cotrimoxazole (73.1\%), minocycline (66.7\%) and cefuroxime (54.2\%). Campylobacter jejuni also exhibited resistance to erythromycin (87.5\%), doxycyclin (75\%), ampicillin (73.7\%), cotrimoxazole (73.3\%) and minocycline (68.8\%).

Conclusions: The resistance patterns of Shigella spp. and Campylobacter jejuni reported in this study necessitates the need for a comprehensive multiregional investigation to evaluate the geographical prevalence and antimicrobial resistance distributions of these microorganisms. These findings also support the need for the discovery and development of effective therapeutic alternatives.
\end{abstract}

Trial registration: Retrospectively registered. Certificate No. 00762

Keywords: Campylobacter jejuni, Shigella, Diarrhoea, Antibiotic resistance

\footnotetext{
* Correspondence: lizzymwamburi@hotmail.com

${ }^{2}$ Department of Biological Sciences, University of Eldoret, P.O. Box 1125, Eldoret 30100, Kenya

Full list of author information is available at the end of the article
}

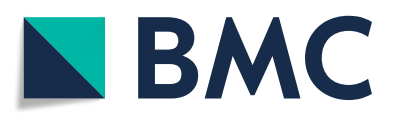

(- The Author(s). 2021 Open Access This article is licensed under a Creative Commons Attribution 4.0 International License, which permits use, sharing, adaptation, distribution and reproduction in any medium or format, as long as you give appropriate credit to the original author(s) and the source, provide a link to the Creative Commons licence, and indicate if changes were made. The images or other third party material in this article are included in the article's Creative Commons licence, unless indicated otherwise in a credit line to the material. If material is not included in the article's Creative Commons licence and your intended use is not permitted by statutory regulation or exceeds the permitted use, you will need to obtain permission directly from the copyright holder. To view a copy of this licence, visit http://creativecommons.org/licenses/by/4.0/ The Creative Commons Public Domain Dedication waiver (http://creativecommons.org/publicdomain/zero/1.0/) applies to the data made available in this article, unless otherwise stated in a credit line to the data. 


\section{Background}

Globally, diarrhoeal diseases is the second most common cause of death in children under five years of age. Each year, about 2.4 million children under five years of age die from diarrhoeal diseases. The highest mortality from diarrhoeal diseases occur in developing countries [1]. In Kenya, diarrhoea is the third most common cause of mortality and morbidity with a case fatality of up to $21 \%$ in children $<5$ years and about $50-60 \%$ of cases are caused by bacterial pathogens [2]. Recent surveys indicate that of the 165 million cases of diarrhoea caused by Shigella that occur annually, 99\% occur in developing countries with $69 \%$ in children under five years of age [3]. It has also been determined that $C$. jejuni is emerging to be one of the most common causes of human diarrhoeal disease and the leading cause of bacterial gastroenteritis in humans worldwide [4].

Although most diarrhoeal diseases are self-resolving and should not be treated with antimicrobial agents, it's still significant that the control of fecal-orally transmitted pathogens is inadequate in many developing countries, in particular, in sub-Saharan Africa, leading to non-empirical selection of antibiotics. Studies reveal that acquired resistance to antimicrobial drugs is becoming more prevalent among enteric pathogens in this region. Improved antimicrobial drug stewardship is an often cited, but inadequately implemented [5]. Resistance to antimicrobials is a growing crisis in clinical medicine. In 2017, the WHO published a list of bacteria where new antibiotics to tackle them are needed urgently and grouped them according to their priority as critical, high, and medium [6]. The use of antibiotics for the successful treatment of infectious diarrhoea has been severely compromised due to the emergence of multidrug-resistant bacteria, a problem that has been acknowledged on a global scale [1]. Currently, there are virtually no antibiotics for the treatment of infections caused by some multidrug-resistant bacterial strains $[7,8]$. Over the years, sulphonamides, tetracycline, ampicillin and trimethoprim/sulphamethoxazole have been effective drugs, only to become impotent in the face of emerging resistance [1]. One class of antibiotics whose clinical efficacy is particularly diminished due to an increase in the prevalence of resistant bacteria are the aminoglycosides such as streptomycin, gentamicin, tobramycin, kanamycin and amikacin [9]. Previously, a single dose of the quinolones: norfloxacin and ciprofloxacin were effective in treating shigellosis. Nowadays, these quinolones are less effective and newer quinolones or other classes of antibiotics such as cephalosporin derivatives and azithromycin are recommended for treatment [10]. The aminoglycosides are highly effective broad-spectrum antimicrobial agents; however, their efficacy has diminished due prevalence of aminoglycoside resistance enzymes in Gram-negative pathogens, the adenylyl transferase ANT (2")-la, that confers resistance to gentamicin, tobramycin, and kanamycin [1].

Initial rates of resistance to new drugs are normally on the order of $1 \%$ but with the current use of antibiotics there has been an increase in the number of either inherent or acquired resistance elements that within 8-12 years after wide-spread use, strains resistant to multiple drugs become widespread [11]. Tafa et al., observed that $30 \%$ or more hospitalized patients were treated with one or more courses of antibiotic therapy [12]. With such practices, the inevitable consequence of widespread and injudicious use of antibiotics has seen the emergence of antibiotic-resistant pathogens, resulting in a serious threat to global public health, as there now remains fewer, or even sometimes no effective antimicrobial agents available for the treatment of infections caused by these bacteria [13].

The aim of the current study was to determine the prevalence of antibiotic resistance as well as patterns in sensitivity profiles of Shigella species and Campylobacter jejuni isolated from faecal samples of children under five years of age presenting with diarrhoea at Kapsabet County Referral Hospital.

\section{Methods}

\section{Study design and site}

This hospital based cross-sectional study was conducted for 6 months at the Kapsabet County Referral Hospital in Nandi County, Kenya. The Kapsabet County Referral Hospital serves approximately $90 \%$ of the infants and children under the age of five. According to the Kapsabet County Referral Hospital records, about 11,000 children are treated annually with $5-10 \%$ of these cases presenting with acute diarrhoea.

\section{Study and source population}

The source population were children under five years old admitted with diarrhea from whom the study population was purposively selected during the study period.

\section{Sample size calculation}

The sample size was calculated using a single population formula with the following assumptions; 95\% level of confidence $(p=0.05)$, with proportion of target population at $89.5 \%$ and design effect of 1.96 . The sample size was a total of 144 pediatric patients.

\section{Sample collections}

There were a total of 144 faecal samples were aseptically collected from all the respondent recruited using the purposive sampling technique, during the period of study. Out of these 5 cases had at least one requirement missing and were excluded from the analysis, and thus 
139 samples were subjected through the investigations thus representing $97 \%$ of the total cases observed in the areas of study.

\section{Data collection techniques}

Face to face interview with patient's parents/guardians was conducted using a structured (closed-ended questions) questionnaire to establish baseline demographic characteristics that included gender, age and medical history.

\section{Bacterial isolation and identification}

Faecal samples were aseptically collected from the enrolled participants, placed into the sterile plastic tube and sealed for transportation to the laboratory for microbiological analysis. Samples were analyzed within 20 min after collection as per the WHO. Each sample was examined macroscopically for colour, texture and presence of any extraneous materials, (blood, mucus or watery). A loopful of each sample was cultured in $10 \mathrm{ml}$ Selenite Faeces (SF) broth for enrichment, incubated at $37^{\circ} \mathrm{C}$ for $6 \mathrm{~h}$ and then aseptically subcultured onto MacConkey (MAC) agar, Salmonella Shigella (SS) agar for the isolation of Shigella spp. while Campylobacter (CAMPY) agar was used for the isolation of C. jejuni. The MacConkey and Salmonella Shigella agar cultures were incubated at $37^{\circ} \mathrm{C}$, aerobically for $18 \mathrm{~h}$. The Campylobacter agar cultures were incubated for $72 \mathrm{~h}$ at $42^{\circ} \mathrm{C}$ in microaerophilic conditions generated by gas pack. The identification of typical colonies from each culture was performed with the use of conventional bacteriological tests for C. jejuni (Hippurate hydrolysis and Commercial identification system) (Api CAMPY system) to confirm and differentiate at the species level. NLF colonies, growing from MAC and SS were selected and subjected to Selected Biochemical Tests (Triple Sugar Iron (TSI), $\mathrm{Hi}-\mathrm{IMViC} / \mathrm{Hi}$ assorted tests (KB001 and KB002 [HIMEDI-INDIA]), Identification of bacteria species was performed according to $\mathrm{WHO}$ recommendations [14]. For each successfully identified isolate, antibiotic susceptibility test was conducted using eleven antibiotic disks specifically ampicillin $(10 \mu \mathrm{g} / \mathrm{disc})$, ciprofloxacin $(30 \mu \mathrm{g} / \mathrm{disc})$, doxycycline $(10 \mu \mathrm{g} / \mathrm{disc})$, erythromycin $(15 \mu \mathrm{g} / \mathrm{disc})$, gentamicin $(10 \mu \mathrm{g} / \mathrm{disc})$, nalidixic acid $(30 \mu \mathrm{g} / \mathrm{disc})$, cefuroxime $(30 \mu \mathrm{g} /$ disc), cotrimoxazole $(25 \mu \mathrm{g} / \mathrm{disc})$, norfloxacin $(30 \mu \mathrm{g} / \mathrm{disc})$, ceftriaxone $(30 \mu \mathrm{g} / \mathrm{disc})$ and minocycline $(30 \mu \mathrm{g} / \mathrm{disc}))$ on Mueller-Hinton agar petri dishes by the Kirby - Bauer Disk diffusion method as per the recommendation of Clinical and Laboratory Standards Institute (CLSI) [15-18]. Zones of growth inhibition were compared to a current zone size on the interpretation table (with the standard cut off measurements for susceptibility resistance) and results were reported either as R (Resistant) or S (Sensitive) [19, 20].

\section{Data quality assurance}

For quality assurance of data, the ward Nurse and clinical officers were instructed to collect data by checking on the provided data sheet. Prior training on proper interview techniques, foecal sampling, foecal processing, quality data collection techniques and adherence to code of ethics and professional conduct was conducted by the interviewer. Routine checks were conducted to ensure that all the components mentioned above were performed accurately.

\section{Data analysis}

Data entry and cleaning were routinely performed using E.P.I 3.5.1 statistical software and then analyzed using SPSS Version 20.0. Frequencies and proportions were computed as descriptive analysis. The isolated pathogens were subjected to descriptive statistics using frequency tables and graphs. The chi-square test and Fisher exact tests were used to determine statistical significance $(p \leq$ 0.05).

\section{Results}

\section{Baseline demographic characteristics}

A total of 139 patients were investigated representing $97 \%$ of the total cases observed in the study area. The patients were categorized according to age into five groups with a sampling interval of 12 months. This grouping method was based on developmental stages, breastfeeding and the weaning ages. About 59\% of the total cases were females while $42 \%$ of the total cases were males. Distribution of age by gender was generally the same in both gender but lowest in males in the 4559 age categories (Table 1 ).

\section{Clinical observation and bacterial isolates}

Majority of the cases 85 (61\%) presented with fulminant diarrhoea and intermittent vomiting while $54(39 \%)$ presented with bloody diarrhoea. About 94 (68\%) cases of diarrhoea samples were mucoid, 19 (14\%) were bloodied while $26(18 \%)$ cases were watery. Bacterial isolations for Shigella spp. were statistically associated with bloody diarrhoea and Campylobacter jejuni correlated significantly $(p=0.0001)$.

Table 1 Distribution of Age by Gender among the cases under study

\begin{tabular}{clllllll}
\hline Gender & \multicolumn{2}{l}{ Age - group (months) } & Total \\
\cline { 2 - 6 } & $\mathbf{0 - 1 1}$ & $\mathbf{1 2 - 2 3}$ & $\mathbf{2 4 - 3 5}$ & $\mathbf{3 6 - 4 4}$ & $\mathbf{4 5 - 5 9}$ & \\
\hline Gender of the child (n\%) & & & & \\
Male & $15(26.3)$ & $19(33.3)$ & $10(17.5)$ & $10(17.5)$ & $3(5.4)$ & $\mathbf{5 7}$ \\
Female & $21(25.6)$ & $25(30.5)$ & $22(26.8)$ & $7(8.5)$ & $7(8.5)$ & $\mathbf{8 2}$ \\
Total & $\mathbf{3 6 ( 2 5 . 8 )}$ & $\mathbf{4 4 ( 3 1 . 7 )}$ & $\mathbf{3 2 ( 2 3 )}$ & $\mathbf{1 7}(\mathbf{1 2 . 2})$ & $\mathbf{1 0 ( 7 . 2 )}$ & $\mathbf{1 3 9}$ \\
\hline
\end{tabular}




\section{Faecal isolates}

Shigella spp. was detected in $50 \%$ of bloody diarrhoeal stool samples and $25 \%$ of the mucoid stool samples. However, C. jejuni was only detected in the mucoid stool samples.

Shigella spp. was the most common pathogen isolated with a frequency of $28(20.1 \%)$ isolates followed by $C$. jejuni with a frequency of $18(12.9 \%)$ (Table 2). Bacterial pathogens were not detected in 82 samples (58.9\%), while 11 samples (10.9\%) produced at least single colonies of non-pathogenic bacteria on MAC agar.

Further cross tabulation of age-group against bacteria pathogens isolated in the study, and controlling for gender (Table 3) found Shigella spp. was more prevalent at both age age-groups of 24-35 months and 12-23 months, indicating a high frequency of Shigella infections. The peak incidence of C. jejuni infection (33.3\%) associated with diarrhoea was observed in age categories of 12-23 months, while Shigella's peak infection (39.3\%) was in the age categories of 24-35 months.

A strong negative significance relationship was established $(r=-0.502, p=0.003)$ between males and bacterial isolates in these age categories. In females, there was no statistical significance established between the age age-group and bacterial isolates $(\mathrm{r}=-0.110, p=0.505)$, indicating no observable difference in age-group and pathogen isolated. An overall significant relationship of $r=-0.289$ was observed, which was significant at $95 \%$ level with $p=0.014$. This indicated that, as the age increases, the number of isolates decreases significantly.

On the correlation of gender with the diarrhoeal etiological agent, female dominated for all agents $(r=0.51)$ indicating no statistical significance between gender and the presence of bacterial pathogens. $(p=0.592)$.

\section{Antimicrobial susceptibility testing (AST)}

Antibiotic inhibition zones were compared with current reference inhibition zones for each bacterial isolate within the limits $[16,20]$. Shigella and $C$. jejuni were resistant to more than $50 \%$ of the test antimicrobials used (Table 4). I Isolates of C. jejuni and Shigella spp. were highly susceptible to ciprofloxacin. Shigella spp. also showed high resistance to ampicillin (82\%), cotrimoxazole (73\%), erythromycin (91.7\%), cefuroxime (54.2\%), minocycline (66.7\%) and doxycycline (83.3\%) (Table 4).

Chi-square $\left(x^{2}\right)$ value of 252.4, $p=0.0001$ indicated that susceptibility patterns demonstrated in this study were statistically significant in relation to the bacterial isolates.

\section{Discussion}

The appropriate treatment of diarrhoeal diseases includes fluid and electrolyte administration. Antimicrobial drug therapy is indicated for children with acute infectious gastroenteritis $[17,20]$. High isolation rates of Shigella spp. (20.1\%) were found in children $<5$ years of old indicates that the bacterium is a common etiological agents implicated in diarrhoea in the area of study under focus. The categories' frequency variations for Shigella spp. and C. jejuni may be explained by differences in age, socio-economic development level, geography, but could also be related to levels of sanitation and individual hygiene, contamination of food or water among other environmental factors. In the current study, Shigella species was detected almost twice as much as $C$. jejuni validating previous reports revealing that shigellosis was prevalent in rural communities [21]. Records of higher prevalence for Shigella species equally replicates with reports of an increasing trend in the prevalence of Shigella infections in sub-Saharan countries in the last ten years [22, 23]. High isolation rates of C. jejuni $(12.9 \%)$ were in agreement with those reported from Kolkata, Algeria [7] and Burkina Faso [24], but also closely compares with studies conducted in South Africa (20.3\%), and Kenya (16.4\%). In other studies, Nigeria reported the highest prevalence $(62.7 \%)$ followed by Malawi (21\%) [25]. The differences in age groups may also be the possible explanations for the variation of the results. On the other hand, lower rates of isolation were reported from some other African countries like Uganda (9.3\%), Madagascar (9.7\%), and Mozambique (1.7\%). Compared with the report from Vhembe district of South Africa (24.9\%), the isolation rate of the current study is lower, due to culture medium used to facilitate the isolation of antibiotics sensitive Campylobacter strains. This level of isolation for Campylobacter jejuni

Table 2 Diarrhoeal types in relation to bacterial pathogen isolated

\begin{tabular}{llll}
\hline & \multicolumn{2}{c}{ Bacteria Isolated Frequency \& percentage (\%) } & \multirow{2}{*}{ Total } \\
\cline { 2 - 3 } & Shigella spp. & C. jejuni & $\mathbf{4 6 / 1 3 9}$ \\
\hline Diarrhoea type & $7(25)$ & $4(22.2)$ & $\mathbf{1 1 / 2 6}$ \\
Watery & $14(50)$ & $0(0)$ & $\mathbf{1 4 / 1 9}$ \\
Bloody & $7(25)$ & $14(77.8)$ & $\mathbf{2 1 / 9 4}$ \\
Mucus+ & $\mathbf{2 8 ( 2 0 . 1 )}$ & $\mathbf{1 8 ( 1 2 . 9 )}$ & $\mathbf{4 6 / 1 3 9}$ \\
Total isolates & &
\end{tabular}


Table 3 Proportional distribution of pathogens in relation to age and gender category

\begin{tabular}{|c|c|c|c|}
\hline Gender of the child & Shigella spp. & C.jejuni & Total \\
\hline \multicolumn{4}{|l|}{ Male } \\
\hline \multicolumn{4}{|l|}{ Age } \\
\hline $0-11$ & $1(8.3)$ & $5(50)$ & $6(27.3)$ \\
\hline $12-23$ & $3(25)$ & $3(30)$ & $6(27.3)$ \\
\hline $24-35$ & $6(50)$ & $1(10)$ & $7(31.8)$ \\
\hline $36-47$ & $1(8.3)$ & $1(10)$ & $2(9.0)$ \\
\hline $45-59$ & $1(8.3)$ & $0(0)$ & $1(4.5)$ \\
\hline Sub-Total & $12(21.1)$ & $10(17.5)$ & 22 \\
\hline \multicolumn{4}{|l|}{ Female } \\
\hline \multicolumn{4}{|l|}{ Age } \\
\hline $0-11$ & $3(18.8)$ & $0(0)$ & $3(12.5)$ \\
\hline $12-23$ & $5(31.2)$ & $3(37.5)$ & $8(33.3)$ \\
\hline $24-35$ & $5(31.2)$ & $3(37.5)$ & $8(33.3)$ \\
\hline $36-47$ & $1(6.3)$ & $2(40)$ & $3(12.5)$ \\
\hline $45-59$ & $2(12.5)$ & $0(0)$ & $2(8.3)$ \\
\hline Sub-Total & $16(19.5)$ & $8(9.7)$ & 24 \\
\hline \multicolumn{4}{|l|}{ Total } \\
\hline \multicolumn{4}{|l|}{ Age } \\
\hline $0-11$ & $4(14.3)$ & $5(27.8)$ & $9(19.6)$ \\
\hline $12-23$ & $8(28.4)$ & $6(33.3)$ & $14(30.4)$ \\
\hline $24-35$ & $11(39.3)$ & $4(22.2)$ & $15(32.6)$ \\
\hline $36-47$ & $2(7.1)$ & $3(16.7)$ & $5(10.9)$ \\
\hline $45-59$ & $3(10.7)$ & $0(0)$ & $6(27.3)$ \\
\hline Total & $28(20.1)$ & $18(12.9)$ & $46(33.1)$ \\
\hline
\end{tabular}

was most probably associated with contact with domestic animals among the study subjects which probably transferred resistant strains of the organisms to children through direct contact or environmental contamination [26]. Slightly more than half $(58.9 \%)$ of the patient stool samples did not yield any bacterial isolates, perhaps due to other diarrhoeal causal agents such as viruses that were not considered during the study, and/ or individual parents/guardians not including a full disclosure of antibiotic use prior to enrolment in the study.

Our results showed that there was no significant difference between infection cases in children below and above12 months of age $(p=0.176)$. This finding is similar to the $46 \%$ prevalence rate earlier reported in Ifakara, Tanzania and Mulago, Kampala both of which agree with the position of the World Health Organization that the vast majority of enteric diarrhoeal cases occur in Asia, Africa and Latin America, where waterborne diseases were highly prevalent because of inadequate supply of potable water to the public with concomitant poor environmental and personal hygiene $[7,8,27,28]$.

Results of our study showed that the number of isolations for Shigella increased with age and reached significant percentages in the $\geq 12$ and $\leq 24$ months age-group for both male and female children. This could be partially due immune system inability to mount an effective immune response and also the risk of placing contaminated fingers and fomites in the mouth is increased due to physiological phenomenon like crawling. The lower shigellosis rate among children under the age of 1 - year - old may be attributed to the protective immune properties of breast milk or the exclusion of Shigella-contaminated foods from their diet. The increased number of shigellosis cases seen over the age of 1 , when most children are no longer breast feeding likely reflects the lack of natural anti- Shigella immunity of recently weaned children [1]. The infections observed in the 0-11 months' group might be explained by possible unhygienic food preparation, food storage and feeding of infants as weaned foods get exposed to contamination. On the other hand, less diarrheal infection was observed with increasing age groups which is consistent with other studies, and this might reflect on possible poor immunity among children invariably due to under nutrition increases susceptibility to diarrheal diseases [2, 8, 9].

About $60 \%$ of the bacterial isolates under focus were multiple antibiotic resistant types, which is in consonance with the detection of multiple-resistant Shigella strains in Africa, England and Asia [29]. Cotrimoxazole is a drug often used for empirical therapy of diarrhoeal diseases, extensive use of this drug may have led to occurrence of resistant Shigella species. In this study Shigella spp. showed a resistant of $73 \%$ to Cotrimoxazole. Previous reports have shown a 92 to $95 \%$ resistant levels to Cotrimoxazole [30]. Campylobacter jejuni was resistant to more than five antibiotics used in this study with a resistance rate of $>50 \%$, indicating a high degree of multiple drug resistance.

Table 4 Resistance of Shigella spp. and Campylobacter jejuni against eleven antibiotics

\begin{tabular}{|c|c|c|c|c|c|c|c|c|c|c|c|}
\hline \multirow[t]{3}{*}{ Bacteria } & \multicolumn{11}{|c|}{$\%$ Antimicrobial resistance } \\
\hline & \multicolumn{11}{|c|}{ Antibiotic } \\
\hline & AMP & CIP & COT & CTZ & CXM & DCN & ERY & GEN & MI & NA & $\overline{\text { NOR }}$ \\
\hline Shigella & 82.1 & 29.9 & 73.1 & 30.8 & 54.2 & 83.3 & 91.7 & 14.8 & 66.7 & 40.7 & 34.6 \\
\hline C. jejuni & 73.7 & 0 & 73.3 & 40.9 & 6.3 & 75 & 87.5 & 36.8 & 68.8 & 36.8 & 6.2 \\
\hline
\end{tabular}

Legend: AMP Ampicillin, CIP Ciprofloxacin, COT Cotrimoxazole, CTZ Ceftriaxone, CXM Cefuroxime, DCN Doxycyclin, ERY Erythromycin, GEN Gentamycin, MI Minocycline, NA Nalidixic acid, NOR Norfloxacin 
The fact that Shigella spp. showed high resistance levels for ampicillin (82\%), cotrimoxazole (73\%), erythromycin (91.7\%), minocycline (66.7\%) and doxycycline (83.3\%), strongly supports that these antibiotics should not be recommended for the treatment of shigellosis. The resistance to ampicillin in Gram-negative bacteria can be explained by the fact that it is primarily mediated by $\beta$-lactamases, within an intergron which hydrolyse the $\beta$-lactam ring and thereby inactivate the antibiotic $[1,12,31,32]$. In East Africa and other African countries, Denmark and Greece low resistance to nalidixic acid and no resistance to ciprofloxacin has been observed in Shigella isolates. Cotrimoxazole is the drug of choice for shigellosis treatment, the resistance pattern in our study could be explained by the presence of a dhfr Ia gene previously described in Shigella and considered the most common dihydrofolate reductase gene in the genus [26, 33, 34]. Low resistance to ciprofloxacin, norfloxacin, ceftriaxone and cefuroxime by Shigella spp. indicates that these drugs may be more effective therapeutic alternatives and further supports the current use of ciprofloxacin, ceftriaxone and nalidixic acid [35,36]. This phenomenon is critical considering the numerous factors that may contribute to resistance by pathogens causing gastroenteritis in developing countries like Kenya. These include frequent overuse, misuse and factors related to the potency and quality of antimicrobials and the distribution of resistant strains [10]. The marked increase in multidrug resistance to first line drugs especially those recommended for the treatment of bacillary dysentery according to WHO [1], and decreased resistance to the newer regimens, ciprofloxacin $(7.7 \%)$ and norfloxacin (28.6\%), may be as a result of a decrease in the use of non-fluoroquinolone agents such as nalidixic acid, in favour of fluoroquinolones for the treatment of both gastroenteritis and undefined febrile illnesses [10]. In addition, this study established a moderate increase in resistance to ceftriaxone, which contrasts with increasing rates of resistance and emergence of extended spectrum $\beta$-lactamase-resistant (ESBL) organisms elsewhere in Africa [37]. Approximately $6.2 \%$ of $C$. jejuni isolates were resistant to norfloxacin, though negligible, points to the emergence of resistance. Comparisons can be made with an increase in cephalosporins resistance rates from 0 to $84 \%$ recorded in Thailand and Nigeria as result of inappropriate and indiscriminate use of that class of drugs $[7,9]$. Campylobacter jejuni was resistant $>50 \%$ of the panel of antibiotics used indicating multiple drug resistance, an appearance which would be a worrying concern globally.

The high percentage of multiple drug resistant Campylobacter jejuni to most frequently used antibiotics may be due to uncontrolled use of antibiotics such as self medicating and access to drugs without prescription [25, 38]. Most of the time, acute gastroenteritis due to
Campylobacter species will be treated empirically with fluoroquinolones and macrolides. Although the rate of Campylobacter spp. resistance to these drugs is increasing in the world, the incidence is higher in developing countries. Use of these drugs for infections other than gastroenteritis and self - medicating is often the cause of resistance in developing countries. In developed countries, resistance is due to their use in food animals and travel to developing countries [26]. Ciprofloxacin resistance among $C$. jejuni in this study may be linked to possible vertical evolution. Mutations in the gyrA gene have also been reported to cause fluoroquinolone resistance in C. jejuni isolates [23, 35].

The problem of antimicrobial drug resistance is not unique to Kapsabet County Referral Hospital. It is particularly critical in many developing countries where frequent illnesses coupled with ready access to unregulated antibiotics diminishes the value of these agents for those patients who actually need them. We found a high frequency of antimicrobial resistance of Shigella spp. and C. jejuni to commonly used antibiotics such as ampicillin (82.1 and 73.7\%) cotrimoxazole (73.1 and 73.3\%) and erythromycin (91.7 and $87.5 \%$ ). This finding is similar to what has been recently described in children from Vietnam, Central Africa, Tanzania, México, Argentina and Mozambique, where high levels of erythromycin and ampicillin resistance was observed for all the tested pathogens $[14,39]$. This is also in agreement with an earlier report of a worldwide occurrence of drug resistant enteric pathogens, a development traceable to inaccurate diagnosis and inappropriate use of these drugs in the treatment of infections $[21,40]$.

\section{Conclusions}

Amidst the emerging increase of Campylobacter jejuni infections in rural Kenya, further and more comprehensive multiregional investigations should be conducted to determine the geographic prevalence and antimicrobial resistance distributions of these microorganisms and many more as causal bacterial agents of diarrhoeal diseases. The presence of multidrug resistant Campylobacter jejuni and Shigella spp. present among $<5$ year children at Kapsabet County Referral Hospital are alarming as most of the first-line and commonly affordable antimicrobial agents like cotrimoxazole, erythromycin and ampicillin were found not to be efficacious of these tested pathogens, thus limiting the therapeutic options in rural-urban areas with limited access of second-line treatment options such as ciprofloxacin and norfloxacin.

\section{Abbreviations}

WHO: World Health Organization; C. jejuni: Campylobacter jejuni; E.

coli: Escherichia coli; spp.: Species; SF: Selenite Faeces; MAC: MacConkey;

SS: Salmonella Shigella; CAMPY: Campylobacter; NLF: Non-lactose fermenters;

TSI: Triple Sugar Iron; CLSI: Clinical and Laboratory Standards Institute; 
ESBL: Extended spectrum $\beta$-lactamase-resistant; AMP: Ampicillin; CIP: Ciprofloxacin; COT: Cotrimoxazole; CTZ: Ceftriaxone; CXM: Cefuroxime; DCN: Doxycyclin; ERY: Erythromycin; GEN: Gentamycin; MI: Minocycline; NA: Nalidixic acid; NOR: Norfloxacin

\section{Acknowledgements}

We are most sincerely grateful to the parents and guardians who consented to have their children participate in this study. We also thank the Laboratory staff at Kapsabet County Referral Hospital who showed great enthusiasm in supporting this study, especially Mr. Gichana Nemwel, who collaborated in the data collection, together with the Clinical Officers and Nursing staff in the pediatric ward. Special thanks to the Medical Superintendent, who granted permission for this study to be conducted in the hospital.

\section{Authors' contributions}

$\mathrm{OZ}$ - conceptualized the study, planned and conducted laboratory work, manuscript writing, ML - conceptualized the study, planned laboratory work, contributed to overall manuscript writing, KR - conceptualized the study and laboratory work, contributed to overall manuscript writing, MA - contributed to overall manuscript development. All the authors read and approved the final manuscript.

\section{Funding}

This study did not receive any external funding.

\section{Availability of data and materials}

The datasets used and/or analysed during the current study are available from the corresponding author on reasonable request.

\section{Ethics approval and consent to participate}

Ethical approval was obtained from the Joint Institutional Research and Ethics Committee (IREC) of Moi Teaching and Referral Hospital (MTRH) and Moi University. The certificate approval number issued was 00762. Informed written consent was obtained from the parents or guardian of the study participants. Participants were allowed to consent without any coercion. For each confirmed infection case, the responsible physicians were informed and appropriate treatment immediately commenced after the samples were collected and diagnosis performed. Information obtained at each stage of the study was kept confidential. Results on isolated pathogens and antibiotic sensitivity thereof were availed to respective clinicians for appropriate patient care.

\section{Consent for publication}

Not applicable.

\section{Competing interests}

The authors declare that they have no competing interests.

\section{Author details}

'Department of Health Services, University of Eldoret, P.O. Box 1125, Eldoret 30100, Kenya. ${ }^{2}$ Department of Biological Sciences, University of Eldoret, P.O. Box 1125, Eldoret 30100, Kenya. ${ }^{3}$ School of Public Health and Community Development, Maseno University, Private Bag, Maseno, Kenya. ${ }^{4}$ Department of Biological Sciences, Moi University, P.O. Box 3900, Eldoret 30100, Kenya.

Received: 9 July 2020 Accepted: 11 January 2021

Published online: 23 January 2021

\section{References}

1. World Health Organization. Antimicrobial resistance: global report on surveillance. World Health Organization; 2014.

2. Brooks JT, Shapiro RL, Kumar L, Wells JG, Phillips-Howard PA, Shi YP, Vulule JM, Hoekstra RM, Mintz E, Slutsker L. Epidemiology of sporadic bloody diarrhoea in rural Western Kenya. Am J Tropical Med Hygiene. 2003;68(6):671-7.

3. O'Reilly CE, Jaron P, Ochieng B, Nyaguara A, Tate JE, et al. Risk factors for death among children less than 5 years old hospitalized with Diarrhea in rural Western Kenya, 2005-2007: a cohort study. PLoS Med. 2012;9(7): e1001256. https://doi.org/10.1371/journal.pmed.1001256.

4. Stef L, Cean A, Vasile A, Julean C, Drinceanu D, Corcionivoschi N. Virulence characteristics of five new campylobacter jejuni chicken isolates. Gut Pathogens. 2013;5(1):1-7.
5. Okeke IN, Aboderin OA, Byarugaba DK, Ojo KK, Opintan JA. Growing Problem of Multidrug-Resistant Enteric Pathogens in Africa. Perspective, Volume 13, Number 11 CDC; 2007.

6. Breijyeh Z, Jubeh B, Karaman R. Resistance of Gram-Negative Bacteria to Current Antibacterial Agents and Approaches to Resolve It. Molecules. 2020; 25:1340. https://doi.org/10.3390/molecules25061340.

7. Nhampossa T, Mandomando I, Acacio S, Quintó L, Vubil D, Ruiz J, et al. Diarrheal disease in rural Mozambique: burden, risk factors and Etiology of diarrheal disease among children aged 0-59 months seeking Care at Health Facilities. PLoS One. 2015;10(5):e0119824. https://doi.org/10.1371/journal. pone.0119824.

8. Mshana SE, Joloba M, Kakooza A, Kaddu-Mulindwa D. Campylobacter spp among children with acute diarrhoea attending Mulago hospital in Kampala-Uganda. Afr Health Sci. 2009;9(3):201.

9. Manirakiza A, Megne-Boudjeka P, Bobossi-Serengbe G, Bercion R, Le Faou A. Prevalence of shigellosis diarrhoea in a paediatrics population: hospital based survey in Bangui, Central African Republic; 2010.

10. Schmieder R, Edwards R. Insights into antibiotic resistance through metagenomic approaches. Future Microbiol. 2012;7(1):73-89.

11. Todar K. Bacterial resistance to antibiotics. Todar's online textbook of bacteriology. 2011; 4.

12. Tafa B, Sewunet T, Tassew H, Asrat D. Isolation and Antimicrobial Susceptibility Patterns of Campylobacter Species among Diarrheic Children at Jimma,Ethiopia. Int J Bacteriol. 2014;2014:560617. https://doi.org/10.1155/ 2014/560617.

13. Padiyara $P$, Inoue $H$, Sprenger M. Global governance mechanisms to address antimicrobial resistance. Inf Dis: Res Treatment. 2018. https://doi. org/10.1177/1178633718767887.

14. World Health Organization, Manual for the laboratory identification and antimicrobial susceptibility testing of bacterial pathogens of public health concern in the developing world. 2003.

15. CLSI. Performance standards for antimicrobial susceptibility testing; eighteenth informational supplement. CLSI document M100-S18. Wayne, PA: Clinical and Laboratory Standards Institute; 2008.

16. Humphries RM, Linscott AJ. Laboratory diagnosis of bacterial gastroenteritis. Clin Microbiol Rev. 2015;28:3-31. https://doi.org/10.1128/CMR.00073-14.

17. Pickering LK. Antimicrobial resistance among enteric pathogens. Adv Exp Med Biol. 2008;609:154-63.

18. Karikari AB, Obiri-Danso K, Frimpong EH, Krogfelt KA. Antibiotic resistance in campylobacter isolated from patients with gastroenteritis in a teaching Hospital in Ghana. Open J Med Microbiol. 2017;7:1-11. https://doi.org/10. 4236/ojmm.2017.71001.

19. Lalitha MK. Manual on antimicrobial susceptibility testing. Performance standards for antimicrobial testing: Twelfth Informational Supplement. 2004; 56238:454-6.

20. Jorgensen JH, Hindler JF, Reller LB, Weinstein MP. New consensus guidelines from the clinical and laboratory standards institute for antimicrobial susceptibility testing of infrequently isolated or fastidious bacteria. Clin Infect Dis. 2007;44(2):280-6.

21. Udo SM, Eja ME. Prevalence and antibiotic resistant Shigellae among primary school children in urban Calabar, Nigeria. Asia Pacific J Public Health. 2004;16(1):41-4. https://doi.org/10.1177/101053950401600107.

22. Niyogi SK. Shigellosis. J Microbiology (Seoul, Korea). 2005;43(2):133.

23. Moore JE, Barton MD, Blair IS, Corcoran D, Dooley JS, Fanning S, Kempf I, Lastovica AJ, Lowery CJ, Matsuda M, McDowell DA. The epidemiology of antibiotic resistance in campylobacter. Microbes Infect. 2006;8(7):1955-66. https://doi.org/10.1016/.jmicinf.2005.12.030.

24. Sangaré L, Nikiéma AK, Zimmermann S, Sanou I, Congo-Ouédraogo M, Diabaté A, Diandé S, Guissou PI. Campylobacter Spp. epidemiology and antimicrobial susceptibility in a developing country, Burkina Faso (West Africa). Afr J Clin Exp Microbiol. 2012;13(2):110-7. https://doi.org/10.4314/ ajcem.v13i2.9.

25. Gahamanyi N, Mboera LEG, Matee MI, Mutangana D, Komba EVG. Prevalence, Risk Factors, and Antimicrobial Resistance Profiles of Thermophilic Campylobacter Species in Humans and Animals in SubSaharan Africa: A Systematic Review. Int I Microbiol. 2020;2020:Article ID 2092478.

26. Tafa B, Sewunet T, Tassew H, Asrat D. Isolation and Antimicrobial Susceptibility Patterns of Campylobacter Species among Diarrheic Children at Jimma, Ethiopia. Int J Bacteriol. 2014), Article ID 560617;2014:7. https://doi. org/10.1155/2014/560617. 
27. Simango C, Nyahanana M. Campylobacter enteritis in children in an urban community. Central Afr J Med. 1997;43(6):172-5.

28. Kosek M, Bern C, Guerrant RL. The global burden of diarrhoeal disease, as estimated from studies published between 1992 and 2000. Bull World Health Organ. 2003;81:197-204.

29. Ajayi OI, Ojo DA, Akinduti PA, Akintokun AK, Akinrotoye KP. Prevalence and antibiotic resistance profiles of serotypes of Shigella species isolated from community children in Odeda local government. Ogun State J Environ Treat Tech. 2019;7(3):270-81.

30. Elnaz A, Abtahi H, van Belkum A, Ghaznavi-Rad E. Multidrug-resistant Shigella infection in pediatric patients with diarrhea from central Iran. Infect Drug Resistance. 2019;12:1535-44

31. Kiptoo MK, Karambu S, Matiru V, Oundo J. Characterization and factors associated with diarrhoeal diseases caused by enteric bacterial pathogens among children aged five years and below attending lgembe District Hospital, Kenya. PanAfrican Medical Journal. 2013;16. https://doi.org/10. 11604/pamj.2013.16.37.2947.

32. Bercion R, Demartin M, Recio C, Massamba PM, Frank T, Escribà JM, Grimont F, Grimont PA, Weill FX. Molecular epidemiology of multidrug-resistant Shigelladysenteriae type 1 causing dysentery outbreaks in Central African Republic, 2003-2004. Trans R Soc Trop Med Hyg. 2006;100(12):1151-8. https://doi.org/10.1016/j.trstmh.2006.02.007.

33. Navia MM, Capitano L, Ruiz J, Vargas M, Urassa H, Schellemberg D, Gascon J Vila J. Typing and Characterization of Mechanisms of Resistance ofShigella spp. Isolated from Feces of Children under 5 Years of Age from Ifakara, Tanzania. J. Clin. Microbiol. 1999:37(10):3113-7.

34. Sang WK, Oundo V, Schnabel D. Prevalence and antibiotic resistance of bacterial pathogens isolated from childhood diarrhoea in four provinces of Kenya. J Infect Developing Countries. 2012;6(07):572-8.

35. Brooks JT, Ochieng JB, Kumar L, Okoth G, Shapiro RL, Wells JG, Bird M, Bopp C, Chege W, Beatty ME, Chiller T. Surveillance for bacterial diarrhoea and antimicrobial resistance in rural western Kenya, 1997-2003. Clin Infect Dis. 2006;43(4):393-401.

36. Kenya Ministry of Public Health and Sanitation. Policy guidelines on control and management of diarrhoeal diseases in children below five years in Kenya. 1-11. Nairobi: Kenya Ministry of Public Health and Sanitation; 2010.

37. Kotloff KL, Nataro JP, Blackwelder WC, Nasrin D, Farag TH, Panchalingam S, Wu Y, Sow SO, Sur D, Breiman RF, Faruque AS. Burden and aetiology of diarrhoeal disease in infants and young children in developing countries (the global enteric Multicenter study, GEMS): a prospective, case-control study. Lancet. 2013;382(9888):209-22. https://doi.org/10.1016/S01406736(13)60844-2

38. Ruiz-Palacios GM. The health burden of Campylobacter infection and the impact of antimicrobial resistance: playing chicken. Clin Infect Dis. 2007; 44(5):701-3 View at Publisher View at Google Scholar.

39. Vargas M, Ochoa TJ, Ruiz J, Molina M, Del Valle LJ, Gil Al, Ecker L, et al. High frequency of Antimicrobial Drug resistance of Diarrheagenic E.coli in infants in Peru. Am J Trop Med Hyg. 2009;81(2):296-301.

40. Aslam B, Wang W, Arshad MI, Khurshid M, Muzammil S, Rasool MH, Nisar MA, Alvi RF, Aslam MA, Qamar MU, Salamat MK. Antibiotic resistance: a rundown of a global crisis. Infect Drug Resistance. 2018;11:1645.

\section{Publisher's Note}

Springer Nature remains neutral with regard to jurisdictional claims in published maps and institutional affiliations.

Ready to submit your research? Choose BMC and benefit from:

- fast, convenient online submission

- thorough peer review by experienced researchers in your field

- rapid publication on acceptance

- support for research data, including large and complex data types

- gold Open Access which fosters wider collaboration and increased citations

- maximum visibility for your research: over $100 \mathrm{M}$ website views per year

At BMC, research is always in progress.

Learn more biomedcentral.com/submissions 